\title{
Interferon-induced sarcoidosis
}

\author{
Cláudia Cardoso, Ricardo Freire, Ana Alves, Ana Oliveira
}

Department of Gastroenterology, Centro Hospitalar de Setúbal, Setúbal, Portugal

Correspondence to Dr Cláudia Sofia Cardoso, claudiamarcal@gmail.com

\section{Summary}

Sarcoidosis is a rare side effect of interferon therapy that has been reported over the last years. We present the case of a 43-year-old man presenting with systemic sarcoidosis during treatment with pegylated interferon and ribavirin. Skin lesions, which were found to be associated with asymptomatic bilateral hilar lymph nodes and pulmonary nodules, were the sole clinical manifestation of the disease. Stopping therapy resulted in clinical and radiological improvement.

\section{BACKGROUND}

Sarcoidosis is a granulomatous disorder of unknown aetiology. During the past three decades, there have been several reports of sarcoidosis developing during interferon treatment for hepatitis $\mathrm{C}$ virus infection. ${ }^{1}$ It is a multisystem disease, with skin and lungs being the most frequently involved organs. The skin lesions may provide the clue for an early diagnosis and in a significant number of patients they are the only manifestation of the disease. ${ }^{2}$ In the majority of cases, interferon-induced sarcoidosis follows a benign course, with clinical remission following dosage reduction or discontinuation of the drug. ${ }^{1}$

\section{CASE PRESENTATION}

A 43-year-old Caucasian man was referred to our department for investigation of chronic hepatitis $C$ virus infection that had been detected in the previous year. He had a history of intravenous drug abuse and was not on any regular prescribed medication. Alanine and aspartate aminotransferases were 1.5 times the upper limit of normal. He had a genotype 1a with a high viral load. Liver histology showed mild chronic hepatitis and portal fibrosis (A3 F1 according to Ishak scoring system). Treatment was started with pegylated interferon $\alpha 2 \mathrm{a}, 180 \mu \mathrm{g}$ subcutaneously once a week and a $1000 \mathrm{mg}$ daily dose of ribavirin. The patient had an early virological response and by week 12 , the viral load remained undetectable. At the sixth month of therapy, he noticed toughening and pigmentation of scars on his back as well as painful erythematous lower limb nodules. On physical examination, scar infiltration and erythema nodosum lesions were confirmed (figures 1A, B). There was no evidence of peripheral lymph node enlargement or hepatosplenomegaly. A biopsy of one of the scars was performed. Histopathologic examination revealed non-caseating granulomas with epithelioid and multinucleate giant cells in the dermis (figures 2A, B). Special stains for bacterial, fungal and mycobacterial organisms yielded negative results. Concomitantly, he had a serum angiotensin-converting enzyme level of $68 \mathrm{U} / 1$ (reference range 8-52 U/1), with a normal calcium level. Chest CT revealed multiple infra-centimetre hilar lymph nodes and two lung nodules in the right upper lobe (figures 3). Pulmonary function tests and the ophthalmologic examination were both normal. A diagnosis of systemic sarcoidosis was established and peginterferon and ribavirin were discontinued. Within a month, an improvement of skin lesions was noticed. A follow-up chest CT scan performed 6 months after treatment cessation showed regression of the previously described lesions. Despite only 6 months of antiviral therapy, a sustained virological response was achieved.

\section{DISCUSSION}

Chronic hepatitis C virus infection affects at least 170 million people worldwide with an increasing number of patients being treated with pegylated interferon $\alpha$ plus ribavirin. ${ }^{3}{ }^{4}$ Several side effects have been described with
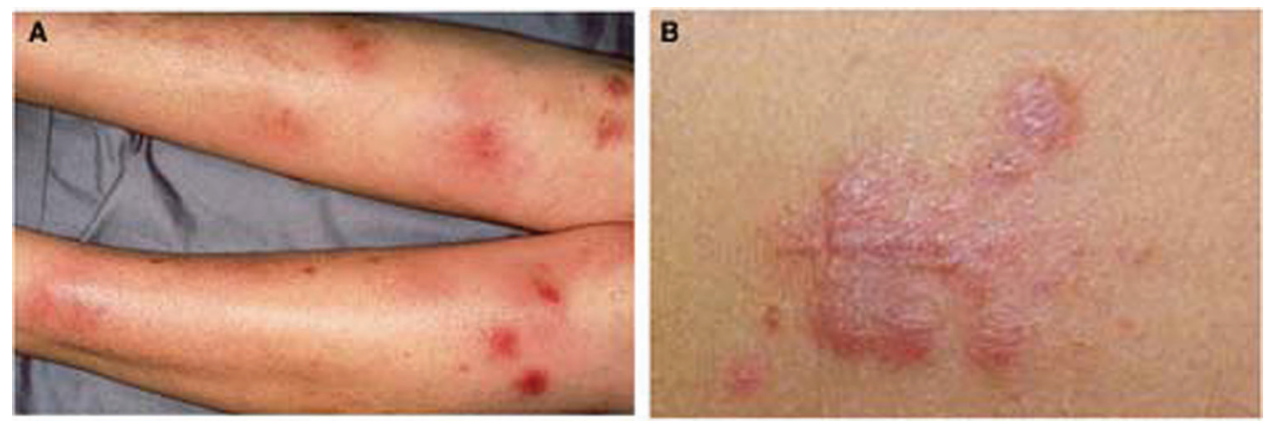

Figure 1 (A) Erythema nodosum lesions in lower limbs. (B) Toughening and pigmentation of a scar. 

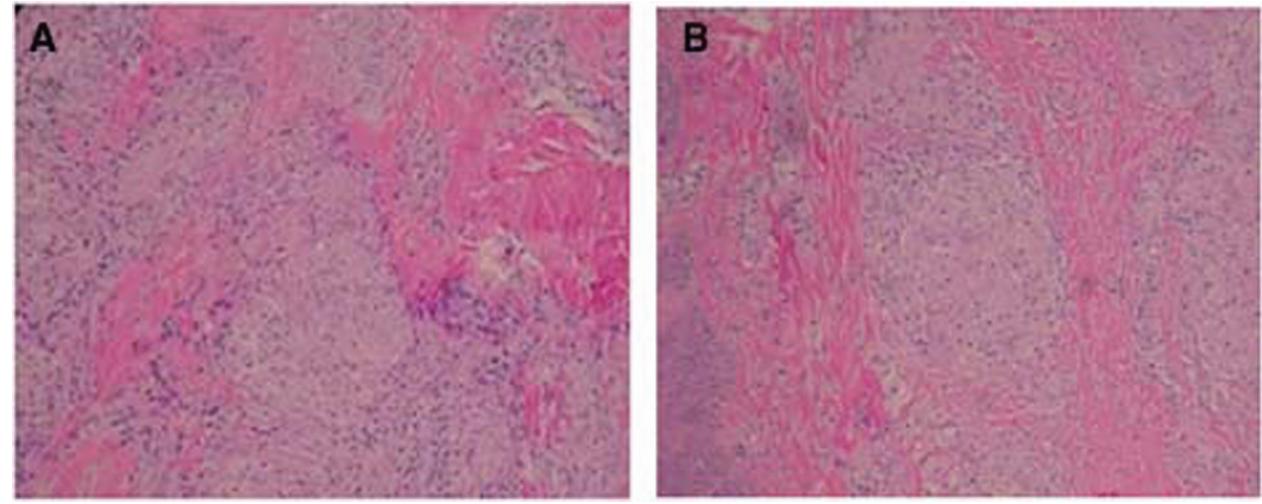

Figure 2 (A, B) Scar biopsy specimen stained with H\&E (original magnification $\times 40$ ) showing non-caseating granulomas with epithelioid and multinucleate giant cells located in the dermis.

interferon therapy. Fatigue, malaise, fever and myalgia are the most common, occurring in $40-55 \%$ of patients, while skin events, including pruritus and rashes, have been reported in up to $20 \% .{ }^{4}$ Immune-mediated diseases such as haemolytic anaemia, hypothyroidism and, during the last years, sarcoidosis, are other reported side effects. ${ }^{1}$ The first case of interferon-induced sarcoidosis was reported in 1987 by Abdi et at ${ }^{5}$ in a patient treated with interferon $\beta$ for renal cell carcinoma. Since then, several cases have been published during interferon treatment for a variety of conditions. In the setting of chronic hepatitis $\mathrm{C}$ virus infection, about 80 cases of interferon-induced sarcoidosis have been published so far. ${ }^{2}$

Sarcoidosis is a systemic disease of unknown aetiology characterised by the presence of non-caseating epithelioid granulomas that can affect any organ. Although the exact cause of the disease remains uncertain, it is thought to represent an exaggerated immune response to an antigen, leading to the activation of antigen-presenting cells with the subsequent release of immune mediators such as interleukines 12 and 15 and tumour necrosis factor- $\alpha$. These cytokines activate CD4+ T lymphocytes towards a T helper type 1 (Th1) immune response, producing large amounts of interferon $\gamma$ and interleukin-2, that appear to be involved in granuloma formation. ${ }^{6-8}$ Interferon- $\alpha$ favours the development and enhancement of Th1mediated responses, which might explain its role in causing sarcoidosis. The case for a causal association is further strengthened by the temporal relation between the introduction of the drug and disease appearance, its remission with therapy cessation and the recurrence of symptoms on re-challenge. ${ }^{1}$ Ribavirin is also able to stimulate Th1 lymphocytes, although cases of sarcoidosis have not been described so far with ribavirin monotherapy. Hepatitis C virus itself has been related to several immune-mediated diseases by promoting a Th1 lymphocyte response, even in the absence of interferon therapy. ${ }^{9}$ However, the remission of sarcoidosis in several patients despite the presence of ongoing viraemia and the failure to find an increased prevalence of hepatitis $C$ virus infection in patients with sarcoidosis strongly argues against an association between these conditions. ${ }^{10} 11$ Indeed, present evidence suggests that ribavirin and hepatitis $C$ virus infection should be considered only as cofactors in interferon-related sarcoid reactions. $^{2}$

Interferon-induced sarcoidosis has a slight female predominance, similar to primary sarcoidosis, although affecting older individuals with a mean age of about 50 years. ${ }^{12}$ The onset of the disease may occur from 15 days to 30 months after the beginning of treatment but is more common in the third and fourth months of therapy. ${ }^{13}$ It can present with fatigue, weight loss, anorexia and malaise, similar to the constitutional symptoms related to interferon therapy. Lungs and mediastinal lymph nodes are involved in $70 \%$ of the cases, with pulmonary disease presenting usually with dry cough and dyspnoea. The more frequently described radiological findings include pulmonary interstitial infiltrates and mediastinal lymph node enlargement. The second most affected organ is the skin (in about $60 \%$ of the patients). ${ }^{12}$ Subcutaneous nodules are the most common manifestations. Scar and tattoo infiltration, maculopapular rash and erythema nodosum are other reported lesions. ${ }^{14} 15$ Skin involvement may occur either alone, or in association with systemic involvement, being the only clinical manifestation of the disease, in about one third of the patients. ${ }^{2}$

A definite diagnosis of interferon-induced sarcoidosis requires a compatible clinical presentation, histological demonstration of non-caseating granulomas and exclusion of other conditions that may cause a similar picture. Any suspicious skin lesion should be biopsied and, given the high prevalence of abnormal radiological findings in patients with respiratory symptoms, chest x-ray and pulmonary function testing should be obtained. ${ }^{12}$ The vast majority of patients achieve spontaneous resolution after stopping interferon. There are some reports of remission despite continuing therapy, suggesting that interferon may trigger the development of sarcoidosis, but has no role in its maintenance. In general, the decision to continue, lower the dose or stop the treatment should balance the benefits of the therapy against the severity of symptoms. Systemic steroids might be necessary for patients with serious manifestations at presentation or progressive disease. ${ }^{16}$ 


\section{BMJ Case Reports}

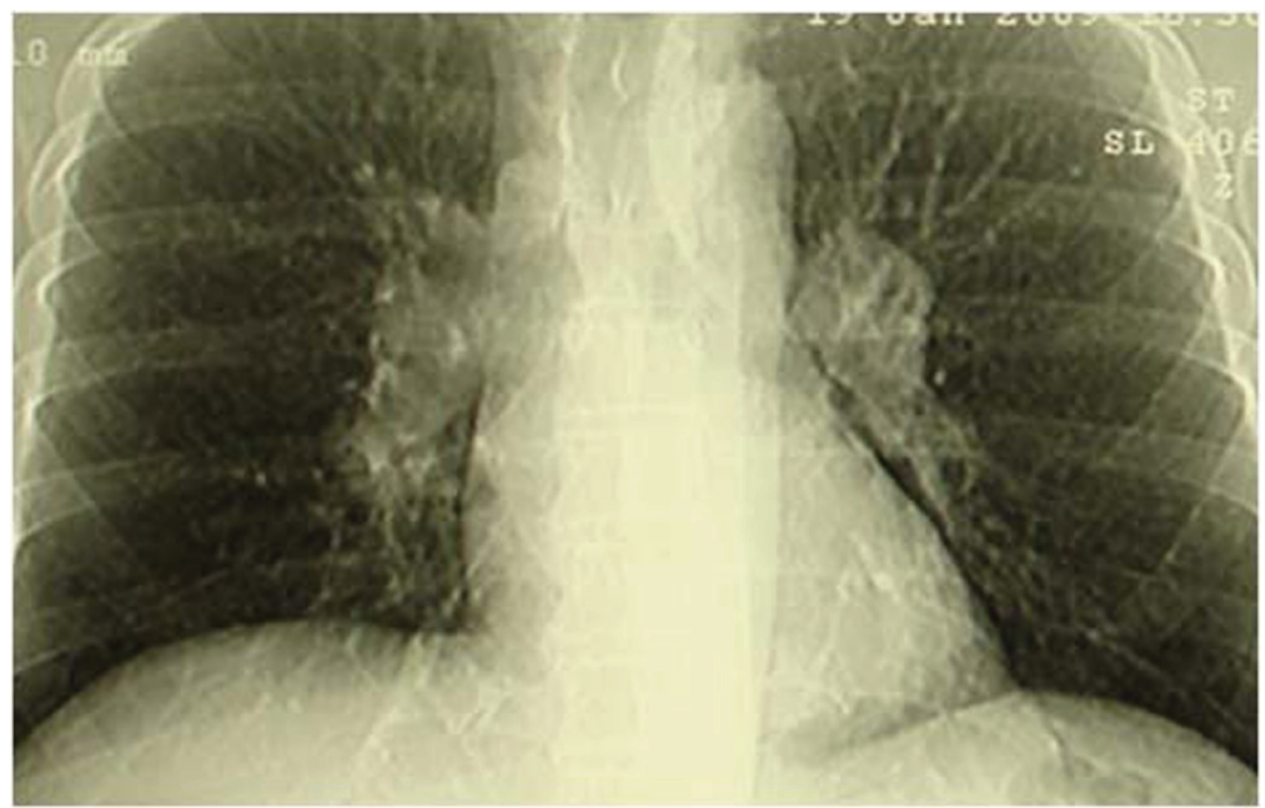

Figure 3 Multiple infra-centimetre hilar lymph nodes.

\section{Learning points}

- Sarcoidosis is a rare but possible side effect of interferon therapy.

- Skin involvement may occur either alone, or in association with systemic involvement, being the only clinical manifestation of the disease, in about one third of the patients.

- Interferon-induced sarcoidosis follows a benign course, with clinical remission following dosage reduction or discontinuation of the drug in the vast majority of patients.

- The decision to continue, lower the dose or stop the treatment should balance the benefits of the therapy against the severity of symptoms.

Competing interests None

Patient consent Obtained.

\section{REFERENCES}

1. Leclerc S, Myers RP, Moussalli J, et al. Sarcoidosis and interferon therapy: report of five cases and review of the literature. Eur J Intern Med 2003;14:237-43.

2. Fantini F, Padalino C, Gualdi G, et al. Cutaneous lesions as initial signs of interferon alpha-induced sarcoidosis: report of three new cases and review of the literature. Dermatol Ther 2009;22(Suppl 1):S1-7.

3. World Health Organization. Global distribution of hepatitis A, B and C, 2001. Wkly Epidemiol Rec 2002;77:6.
4. Poynard T, Yuen MF, Ratziu V, et al. Viral hepatitis C. Lancet 2003;362:2095-100.

5. Abdi EA, Nguyen GK, Ludwig RN, et al. Pulmonary sarcoidosis following interferon therapy for advanced renal cell carcinoma. Cancer 1987;59:896-900.

6. Braverman IM. Sarcoidosis. In: Feedberg IM, Eisen AZ, Wolff K, et al, eds. Fitzpatrick's Dermatology in General Medicine. Sixth edition. New York, NY: McGraw-Hill 2003:1777-83.

7. Robinson BW, McLemore TL, Crystal RG. Gamma interferon is spontaneously released by alveolar macrophages and lung $T$ lymphocytes in patients with pulmonary sarcoidosis. J Clin Invest 1985;75:1488-95.

8. Bäumer I, Zissel G, Schlaak M, et al. Th1/Th2 cell distribution in pulmonary sarcoidosis. Am J Respir Cell Mol Biol 1997;16:171-7.

9. Ramos-Casals M, Mañá J, Nardi N, et al. Sarcoidosis in patients with chronic hepatitis $\mathrm{C}$ virus infection: analysis of 68 cases. Medicine (Baltimore) 2005;84:69-80.

10. Baughman RP, Sharma OP, Lynch JP 3rd. Sarcoidosis: is therapy effective? Semin Respir Infect 1998;13:255-73.

11. Mert A, Bilir M, Ozaras R, et al. The prevalence of serum antibodies to hepatitis $C$ virus is not increased in patients with sarcoidosis. Respiration 2000;67:592

12. Statement on sarcoidosis. Joint Statement of the American Thoracic Society (ATS), the European Respiratory Society (ERS) and the World Association of Sarcoidosis and Other Granulomatous Disorders (WASOG) adopted by the ATS Board of Directors and by the ERS Executive Committee, February 1999. Am J Respir Crit Care Med 1999;160:736-55.

13. Cogrel $\mathbf{0}$, Doutre MS, Marlière $V$, et al. Cutaneous sarcoidosis during interferon alfa and ribavirin treatment of hepatitis $C$ virus infection: two cases. Br J Dermatol 2002;146:320-4.

14. Yanardag H, Pamuk ON, Karayel T. Cutaneous involvement in sarcoidosis: analysis of the features in 170 patients. Respir Med 2003;97:978-82.

15. Sanders S, Busam K, Tahan SR, et al. Granulomatous and suppurative dermatitis at interferon alfa injection sites: report of 2 cases. J Am Acad Dermatol 2002;46:611-16

16. Alazemi S, Campos MA. Interferon-induced sarcoidosis. Int J Clin Pract 2006;60:201-11. 


\section{BMJ Case Reports}

This pdf has been created automatically from the final edited text and images.

Copyright 2011 BMJ Publishing Group. All rights reserved. For permission to reuse any of this content visit http://group.bmj.com/group/rights-licensing/permissions.

BMJ Case Report Fellows may re-use this article for personal use and teaching without any further permission.

Please cite this article as follows (you will need to access the article online to obtain the date of publication).

Cardoso C, Freire R, Alves A, Oliveira A. Interferon-induced sarcoidosis. BMJ Case Reports 2011;10.1136/bcr.03.2011.3929, date of publication

Become a Fellow of BMJ Case Reports today and you can:

- Submit as many cases as you like

- Enjoy fast sympathetic peer review and rapid publication of accepted articles

- Access all the published articles

- Re-use any of the published material for personal use and teaching without further permission

For information on Institutional Fellowships contact consortiasales@bmjgroup.com

Visit casereports.bmj.com for more articles like this and to become a Fellow 